\title{
Design with evaluation in mind: Assuring quality in a newly blended nursing program
}

\author{
Laurie J. Posey ${ }^{* 1}$, Emily O. Egerton ${ }^{2}$ \\ ${ }^{1}$ School of Nursing, The George Washington University, Washington, D.C., United States \\ ${ }^{2}$ School of Nursing, Duke University, Durham, N.C., United States
}

Received: July 5, 2015

DOI: $10.5430 /$ jnep.v6n1p9
Accepted: September 10, $2015 \quad$ Online Published: September 29, 2015

URL: http://dx.doi.org/10.5430/jnep.v6n1p9

\begin{abstract}
As traditionally face-to-face nursing programs integrate more and more online components into the curriculum, it is important to consider established standards of quality in online and blended course design. This case study applied a quality rubric and peer-review process to the design and evaluation of a newly blended Accelerated Bachelor of Science in Nursing (ABSN) program. Early adoption of the standards to guide the redesign process resulted in a highly successful review process, with twelve of thirteen courses achieving quality certifications. Qualitative analysis of peer review feedback revealed common themes including: the importance of greeting students with a warm and professional welcome; ensuring alignment among objectives, activities \& assessments; establishing a context for instructional units; guiding student use of learning materials; promoting active learning; and developing specific, detailed criteria and grading rubrics for assessments. Despite several challenges associated with applying an online-focused process to blended courses, the selected framework was a useful for assuring quality in the design and evaluation of both fully online and blended nursing courses.
\end{abstract}

Key Words: Nursing education, Blended learning, Online learning, Quality assurance, Quality improvement, Peer-review, Instructional design

\section{INTRODUCTION}

Blended educational programs combine online and face-toface learning experiences, ideally in a way that optimizes the educational benefits of both teaching environments. ${ }^{[1]}$ Blended learning enables nurse educators to flexibility integrate innovative online teaching approaches into the curriculum, while continuing to meet students' needs for instructorguided clinical experiences. Moving foundational learning content online can increase opportunities for active learning in the classroom to support higher-order learning objectives. $^{[2-5]}$ The addition of self-directed online learning experiences can also increase student accountability and foster independent learning skills. ${ }^{[6,7]}$ As traditionally face-to-face programs integrate more and more online components into the nursing curriculum in an effort to realize these benefits, it is important to consider established standards of quality in online and blended course design.

This case study describes the use of an established quality framework to guide the design and evaluation of a newly blended Accelerated Bachelor of Science in Nursing (ABSN) program. The transition to blended learning was funded by a grant from the United States Health Resources and Services Administration (HRSA). The grant work included faculty peer reviews of the redesigned courses as one demonstration States.

*Correspondence: Laurie J. Posey; Email: posey@gwu.edu; Address: School of Nursing, The George Washington University, Washington, United 
of program outcomes. Adopting a quality framework and peer review process at the start of the project facilitated a consistent design approach that culminated in positive outcomes and a high quality blended program.

\section{Background}

Efforts to measure the quality of online and blended courses have evolved over the years from theoretically-based frameworks and papers that discuss best practices, to published rubrics that assess and evaluate specific criteria related to successful student outcomes. ${ }^{[8]}$ Quality assessments have examined content quality; adequacy of delivery support functions for instructors, administrators and students (including those with physical, visual and/or auditory limitations); effectiveness of pedagogically-driven instructional design; web site usability and access needs; and technological support. ${ }^{[9,10]}$ Other recognized factors that impact quality of online and blended instruction include student motivation and involvement, student-directed learning, student-faculty contact, cooperation among students, active learning, prompt feedback, and communication of high expectations and respect for diverse talents and learning styles. ${ }^{[11,12]}$

Several national organizations have defined standards to guide quality in the implementation of online programs at the institutional level. Recognizing that successful implementation of distance education extends beyond the efforts of an individual instructor, the Institute for Higher Education Policy identified 24 quality benchmarks categorized in seven areas: institutional support, course development, teaching/learning process, course structure, student support, faculty support, and evaluation and assessment. ${ }^{[13]}$ Similarly, the Online Learning Consortium's Quality Scorecard includes eight categories of quality metrics: institutional support, technology support, course development/instructional design, course structure, teaching and learning, social and student engagement, and student support. ${ }^{[14]}$

Many higher-education institutions with well-established online learning programs have devised their own quality frameworks. Some of the more well-known institutional models include the University of Illinois's Quality Online Course Initiative Rubric and Checklist (QOCI) ${ }^{[15]}$ Central Michigan University's Quality Assurance Checklist, ${ }^{[16]}$ Monterey Institute's Online Course Evaluation Project (OCEP), ${ }^{[17]}$ the University of Southern Mississippi's Online Course Development Guide and Rubric, ${ }^{[18]}$ Chico's Rubric for Online Instruction (ROI) from California State University, ${ }^{[19]}$ Michigan Community College Association's Online Course Development Guidelines and Rubric, ${ }^{[20]}$ Western Carolina's Online Course Assessment Tool (OCAT), ${ }^{[21]}$ and MacEwan University's Checklist for Online Interactive Learning (COIL). ${ }^{[22]}$
While several of these evaluation rubrics have been empirically researched and validated, they have not always been widely available or accessible. One of the more wellestablished quality frameworks is Quality Matters (QM), which consists of a faculty-driven peer review process based on a rubric of research-based standards of best practice in online and blended course design. The QM rubric is organized into eight general standards: Course Overview and Introduction, Learning Objectives (Competencies), Assessment and Measurement, Instructional Materials, Learner Interaction and Engagement, Course Technology, Learner Support, and Accessibility. ${ }^{[23]}$ As evidenced by its large and diverse base of subscribers - over 900 as of May, 2015 - QM has been widely adopted by academic institutions both nationally and internationally (www .qualitymatters.org).

Despite this broad reach, published research describing the QM rubric's use and effectiveness for evaluating online and blended courses is somewhat limited, particularly as it relates to program-wide implementation. Parscal and Riemer describe large-scale quality initiatives at two institutions that have benefitted from the integration of the QM standards within instructional design, professional development and internal and external course review processes. ${ }^{[24]}$ Another institution integrated the QM criteria with an active-mastery learning model to guide the instructional design of online courses. ${ }^{[25]}$ Finley reflected on using the QM rubric to improve student navigation and ease of use, clarify the purpose of learning activities for students, and ensure alignment among assessments and activities, and improve accessibility within her own courses. ${ }^{[26]}$ Other studies in the literature describe QM's utility as a foundation for faculty development and mentoring to assure quality in the design of new online courses. ${ }^{[27,28]}$ Shattuck's summary of QM-sponsored research reinforced the value of the framework in guiding the design of high-quality online courses, as well as its potential to positively influence student learning and satisfaction. ${ }^{\text {[29] }}$

Among the varied quality frameworks, QM is unique in its inclusion of specific annotations linking the quality criteria to blended course design and was therefore adopted to guide both the early design and subsequent faculty peer reviews of the newly-blended courses. Our experience using this framework as a tool for overall quality assurance underscores the benefit of adopting an established set of quality standards up front. Applying key best practices consistently across all courses helped to streamline the design and development process and resulted in a high quality blended learning program.

\section{Methods}

This case study applied the 2011-2013 version of the QM rubric and peer-review process to inform the redesign and 
evaluate the quality of a second-degree, ABSN academic program. ${ }^{[30]}$ The rubric standards were carefully considered in planning the online components for eight newly blended courses. These, along with five fully online courses that were already part of the program, were peer-reviewed by faculty teams using the QM rubric. Participants included twelve faculty developers, seven peer reviewers, and two review team chairpersons.

Guided by a team of instructional and multimedia designers, the nursing faculty members assumed primary responsibility for redesigning their course(s). The instructional design team also provided the faculty with the QM rubric as well as a standard syllabus and course template based on the standards. These templates enabled faculty developers to convert their courses efficiently while ensuring consistent, high-quality course designs.

In collaboration with instructional designers, faculty developers designed their blended courses using a systematic approach that integrated the quality standards with the Analysis, Design, Development, Implementation and Evaluation (ADDIE) instructional design model. ${ }^{[31]}$ During the Analysis phase, an instructional designer (ID) met with each faculty member to discuss how online components could be most effectively integrated with classroom experiences to achieve course goals and objectives. During this meeting, the ID reviewed the rubric standards and annotations and reinforced the importance of alignment among course and session-level objectives, learning activities, course materials and assessments. During the Design phase, faculty wrote learning objectives and planned online and classroom activities for each course session. During the Development phase, nursing faculty and IDs worked together to produce multimedia components and populate the Blackboard online classroom.

Once taught, archived versions of the blended courses were evaluated using the formal QM peer-review process. QM requires that each faculty peer review team include a chairperson who has experience as a QM Peer Reviewer and has been certified as a QM Master Reviewer, and two other reviewers who have been certified as QM Peer Reviewers. On each review team, one peer reviewer must be a subject-matter expert and one peer reviewer must be external the institution. To streamline this process, the project team identified two QM-certified Master Reviewers from outside of the institution to serve as chairs for the reviews. Five faculty members certified as QM Peer Reviewers were assigned to different reviews in the roles of subject-matter experts or general reviewers. The faculty course developers were also engaged in pre-review discussions and consulted during the reviews as needed. Review team members were given access to the archived courses and completed their reviews using QM's online course review management system.

In the first part of the review process, peer reviewers individually evaluated the archived online courses and online portions of the blended courses to assess the degree to which they met each of the quality standards in the QM rubric. The rubric included 41 standards organized in eight categories: Course Overview and Introduction, Learning Objectives, Assessment and Measurement, Instructional Materials, Learner Interaction \& Engagement, Course Technology, Learner Support and Accessibility. Of the 41 specific standards, 21 were considered essential and required in order for the course to achieve QM certification. For each standard, reviewers determined whether or not each course met the standard at an $85 \%$ level, and indicated "Yes" if it did, and "No" if it did not. In addition, for each standard, reviewers added comments related to why they felt the course did or did not meet the standard, along with recommendations for improvement.

Once members of a course review team completed their individual assessments, the online management system generated a summary report that consolidated the ratings and comments for each review standard. The team chair then reviewed this report to ensure that reviewer comments were constructive and identified any discrepancies among the individual reviews. The chair then convened a post-review meeting to discuss the overall evaluation of the course's strengths and areas for potential growth. Although a standard is considered met or not met if two or more members of the review team agree, this post-review meeting allowed each team member to discuss and justify his or her opinion and/or rating. In some cases, this verbal clarification informed reviewers' decisions to change how they scored a standard. After the meeting, each reviewer revised scoring as needed to reflect decisions made in the meeting.

To achieve QM certification, courses were required to meet 21 essential standards and achieve 81 out of a possible 95 points in the overall evaluation. If a course had unmet standards that could be easily addressed, the faculty developer was notified and provided the opportunity to make revisions to the course before the formal course evaluation was submitted. Once notified by the faculty developer that necessary changes were made, the reviewers then re-checked the archived course for verification and revised their reviews accordingly. The peer reviewers then submitted their final reports to the online management system, which subsequently notified the team chair to conduct one final review before submitting the final report. If the course did not meet standards on the first review, the faculty developer was required to submit an amendment form summarizing revisions to be made 
to the course. Once the revisions were made, the team chair reviewed the course to ensure that it now met the standards, and approved the amendment form.

\section{Results}

After minor revisions based on early reviewer feedback, eleven of the thirteen courses met the standards required to achieve QM certification. One course required an amendment cycle in order to achieve recognition. The one course that did not meet standards was subsequently removed from the curriculum for reasons unrelated to the QM review, and therefore, no additional efforts were made to achieve certification for this course.

Table 1. QM course review outcomes

\begin{tabular}{lllll}
\hline Course Name & Format & Review Outcome & Score* & Date \\
\hline Transition to the Nursing Profession & Blended & Met Standards 1st Review & 93 & $7 / 31 / 13$ \\
Health Assessment & Blended & Met Standards 1st Review & 92 & $8 / 6 / 13$ \\
Adult/Aging Acute \& Chronic Illness & Blended & Met Standards 1st Review & 92 & $8 / 15 / 13$ \\
Adv Adult Medical-Surgical Nursing & Blended & Met Standards 1st Review & 93 & $4 / 30 / 14$ \\
Maternity and Women's Healthcare & Blended & Met Standards w/Amendment & 85 & $1 / 11 / 13$ \\
Psychiatric Mental-Health Nursing & Blended & Met Standards 1st Review & 95 & $10 / 22 / 13$ \\
Epidemiology \& Community Health & Blended & Met Standards 1st Review & 95 & $6 / 6 / 14$ \\
Children and Families & Blended & Met Standards 1st Review & 92 & $4 / 17 / 14$ \\
Patient Safety \& Health Care Quality & Online & Met Standards 1st Review & 93 & $2 / 15 / 13$ \\
Theoretical Foundations in Nursing & Online & Did Not Meet Standards & 68 & N/A \\
Nursing Leadership & Online & Met Standards 1st Review & 95 & $2 / 6 / 13$ \\
Health Information and Technology & Online & Met Standards 1st Review & 93 & $6 / 29 / 14$ \\
Research Methods for Health Prof. I & Online & Met Standards 1st Review & 93 & $6 / 11 / 13$ \\
\hline
\end{tabular}

*Total Points Possible $=95$

As shown in Table 1, most of the courses achieved at least 92 of the 95 possible points. The reviews were completed over a 1.5-year period, with each review taking 3-4 weeks to complete.

Reviewer feedback related to each of the general QM standards was analyzed qualitatively using a descriptive qualitative method. ${ }^{[32]}$ Reviewer comments from the final review reports were organized by category related to each standard, and then synthesized to identify common themes. These themes include common best practices and suggestions for improvement, as well as anomalies that emerged related to the application of the QM standards to blended (as opposed to fully online) courses.

QM General Standard 1: Course Overview and Introduction requires that the overall design of the course is made clear to the student at the beginning of the course. Commonly noted best practices related to this standard included greeting students with a warm welcome and brief introduction to the course. Recommendations for improvement included clearer explanation of how the instruction in the blended courses would be structured across face-to-face and online time, and increasing the use of video $v s$. text introductions to enhance instructors' online presence and connection with the students.

QM General Standard 2: Learning Objectives requires that all learning objectives are clearly stated and measurable and that course and session-level objectives are aligned. All of the courses were designed with these principles in mind, and the learning objectives generally met this standard. With respect to alignment, reviewer comments highlighted a need for objectives at the session level to appropriately reflect the level of critical thinking involved in many of the short and long-term activities and projects. For example, a lower-order objective (e.g., describe a treatment approach) was often supported by a learning activity demanding higher-order reasoning skills (e.g., applying the treatment approach to a case study). Another recommendation was for instructors to add an introduction to each session to help students understand the relationship between the course and session-level objectives and guide them in achieving learning goals.

QM General Standard 3: Assessment and Measurement requires that assessment strategies be designed to evaluate student progress related to learning objectives; to measure the effectiveness of student learning; and to be integral to the learning process. Among the courses reviewed, reviewers consistently acknowledged that the instructors developed 
and employed a wide variety of assessment strategies to measure achievement of course and session outcomes. Reviews reinforced the importance of clearly specifying criteria for assessment. While many courses included grading rubrics, this was not consistent across all courses assignments, and the addition of detailed rubrics for all assignments emerged as an important best practice.

QM General Standard 4: Instructional Materials, requires that instructional materials be aligned with and sufficiently comprehensive to contribute to the achievement of learning objectives. While all of the courses provided learning materials that supported objectives, activities and assignments, one consistent recommendation was to begin each session with an overview of what each session is about, how it relates to or builds on previous sessions, and how the learning materials contribute to students' achievement of the learning objectives.

QM General Standard 5: Learner Interaction and Engagement, emphasizes active engagement among faculty, students and the course content. In general, all of the courses included high degrees of student engagement in the form of cooperative learning activities, critical thinking discussions, case studies and problem-based learning. For the blended courses, most of this interaction took place in the classroom, which was a challenge given that the reviews were limited to online course components. The reviewers relied upon descriptions of activities within the course syllabus as well as some communication with the course instructors as evidence that this standard was met.

QM General Standard 6: Technology, ensures that course navigation is logical, consistent and intuitive, that course technologies are current and available, and that the technologies within learning management systems (LMS) are used to facilitate and support the student learning experience. All of the courses were delivered in the latest version of the Blackboard LMS and included a consistent, easy to navigate menudriven structure. One challenge that emerged for this standard related to the criteria that course media shoul promote active learner engagement. Many of the blended courses used technologies such as narrated lectures and videos, traditionally viewed as passive teaching tools, to promote active learning using a "flipped classroom" approach. Reviewers relied upon communication from the instructor as evidence that these technologies were being used to support active learning. A resulting recommendation was for the blended courses to provide additional explanation within the online classroom about the purpose of these materials as they relate to the active learning experience.

QM General Standard 7: Learner Support, requires that courses facilitate student access to technical, academic and student support services. Because the standard syllabus included a description along with links to various institutional resources, all of the courses met this standard. One theme that emerged was a need for additional detail related to how each service could help students succeed in the course.

QM General Standard 8: Accessibility, focuses on ensuring that course materials are designed and delivered to accommodate students with special needs and learning challenges. All of the courses provided information about how to receive accommodation through the Office of Disability Support Services, and most of the content presented within the courses was provided in an accessible format. One common area of weakness was a lack of transcripts for multimedia content. To address this requirement, instructors often provided a downloadable version of presentations with supplemental notes related to the audio script; however, the review process underscored the need for a more consistent and precise way of providing alternative text for media presentations.

\section{DiscuSSION}

Adopting a quality framework up front was beneficial as a foundation for high-quality course designs that ultimately led to the certification of all but one of the blended and online courses within the ABSN program. This finding was consistent with observations from previous research that highlighted the benefits of the QM rubric in guiding online course design. ${ }^{[33,34]}$ The use of rigorous and well-supported review tools and processes allowed for a thorough and streamlined program evaluation process. Conducting reviews of many courses (in contrast to conducting a single course review) revealed common areas of need that led to program- and school-wide improvements and best practices.

The review teams encountered several challenges when applying the QM process and rubric to the blended courses, primarily due to the fact that the peer reviews focused on evidence provided within the online portions of the courses. For example, although the course syllabi and online materials provided a general overview of the relationship between classroom and online methodologies, the review team knew little about the detail of learning activities that were planned for the face-to-face classroom sessions, and more importantly, what actually took place in the classroom. Similarly, because all the blended courses reviewed in this study had activities that involved student engagement in cooperative learning activities, case studies, and problem-based learning in the face-to-face meetings, they met the criteria for learner interaction and engagement. However, because there was no requirement to observe this in the face-to-face portion of the courses, the review team needed to rely upon descriptions 
within the course and communication with the instructor as evidence of active learning. This is consistent with Shattuck's conclusion that "too often the relationship between course design and other components of quality assurance is neglected in the interest of focusing on QM as a stand-alone measure of quality". ${ }^{[35]}$ For blended courses in particular, it would be advisable to supplement the online reviews with a classroom observation review process.

When applying QM to the design and evaluation of blended courses, it is also important to consider that students in many blended courses interact regularly face-to-face, both formally and informally. Some standards called for online course components that were redundant with activities that took place in the classroom. For example, both students and instructors would likely view strict adherence to some standards, such as including online student introductions for the benefit of those who may have missed them in the classroom, as superfluous. Providing online introductions for each weekly session is another example. Although establishing a context for learning is essential in a fully online course, in the blended courses studied, this often took place more organically in the classroom. One might argue that the face-to-face environment that allows faculty to observe students' reactions and gives students the opportunity to ask questions in real time is more conducive to this kind of discussion. That being said, the online portions of a blended course should not be limited to posting instructional content and passive absorption of materials. Standards that promote varying learning activities and interaction among instructors and students can be beneficial in stimulating more creative use of online interactive and collaborative activities within blended course designs.

Consideration of the standards in the course designs also added a useful level of detail and structure to the blended courses that might otherwise have been overlooked. For example, instructors who regularly interact with students in the classroom might communicate expectations for giving feedback and grading somewhat casually in a face-to-face environment. Standards calling for written communication of these expectations forced instructors to think about and commit to the mechanisms and timing of providing feedback and grading assignments, which reduced the possibility of miscommunication about this important aspect of quality teaching.

\section{Conclusions}

The outcomes of this project underscore the importance of instructional design with evaluation in mind. Adopting an established set of quality standards up front, and providing faculty with templates and guidance to aid them in integrating the standards into their course designs, fostered an efficient redesign process and resulted in a high quality blended ABSN program. Adopting the standards at the start of the program led to the integration of common syllabi components, orientation materials, and links and information about accessing academic, technical and other student supports that helped to ensure that expectations were clearly set and diverse student needs were met in all courses. In addition to guiding the redesign of blended courses, reviewing courses with a fresh eye toward alignment among objectives, activities and assessments fostered positive curricular change.

Given the challenges associated with limiting the reviews to the design of the online portions of the courses, nursing programs interested in a holistic approach to quality assurance should consider supplemental review tools and processes that focus on how the instructor facilitates learning and interacts with students during course delivery, whether online or face to face. Despite this limitation, it is clear that early adoption of research-based best practices and design standards is useful in guiding the design and evaluation of both fully online and blended courses. Common themes emerging from the review of thirteen courses through a common lens reinforced the importance of greeting students with a warm and professional welcome; ensuring alignment among objectives, activities \& assessments; establishing a context for instructional units; guiding student use of learning materials; promoting active learning; and providing specific, detailed criteria and grading rubrics for assessments. These instructional design best practices transcend course format and are equally applicable to face-to-face, blended and fully online delivery.

\section{ACKNOWLEDGEMENTS}

This study was supported by funds from the Division of Nursing (DN), Bureaus of Health Professions (BHPr), Health Resources and Services Administration (HRSA), Department of Health and Human Services (DHHS) under grant number D11HP22190. The information or content and conclusions are those of the authors and should not be construed as the official position or policy of, nor should any endorsements be inferred by the DN, BHPr, HRSA, DHHS or the U.S. Government.

\section{CONFlicts of InTEREST Disclosure}

The authors declare that there is no conflict of interest. 


\section{REFERENCES}

[1] Garrison DR, Vaughan ND. Blended learning in higher education: Framework, principles, and guidelines. San Francisco: Jossey-Bass; 2008. 245p.

[2] Ferreri SP, O'Connor SK. Redesign of a large lecture course into a small-group learning course. Am J Pharm Educ. 2013; 77(1): 13. PMid:23459199 http://dx.doi.org/10.5688/ajpe77113

[3] Mason GS, Shuman TR, Cook KE. Comparing the effectiveness of an inverted classroom to a traditional classroom in an upper-division engineering course. IEEE Trans on Educ. 2013; 56(4): 430-435. http://dx.doi.org/10.1109/TE. 2013.2249066

[4] Pierce R, Fox J. Vodcasts and active-learning exercises in a "flipped classroom" model of a renal pharmacotherapy module. Am J Pharm Educ. 2012; 76(10): 196. PMid:23275661 http://dx.doi.org/1 0.5688 /ajpe7610196

[5] Redekopp M, Ragusa G. Evaluating flipped classroom strategies and tools for computer engineering. Paper presented at: 120th ASEE Annual Conference and Exposition. 2013. Available from: http://www.asee.org/public/conferences/20/pap ers/7063/download

[6] Abdulla D. Attitudes of college students enrolled in 2-year health care programs towards online learning. Computers \& Education. 2012 Dec; 59(4): 1215-1223. http://dx.doi.org/10.1016/j.compe du. 2012.06.006

[7] McDonald K, Smith CM. The flipped classroom for professional development: part I: Benefits and strategies. J Contin Educ Nurs. 2013 Oct; 44(10): 437-8. PMid:24098988 http://dx .doi .org/1 $0.3928 / 00220124-20130925-19$

[8] Jaggers D, Xu SS. Adaptability to online learning: Differences across types of students and academic subject areas. $\mathrm{J}$ of Higher Educ. 2014; 85(5): 633-659. http://dx.doi.org/10.1353/jhe.201 4.0028

[9] Oblinger DG, Barone CA, Hawkins BL. Distributed education and its challenges: An overview. American Council on Education and EDUCAUSE. 2001. Available from: http://www . acenet.edu/news-room/Documents/Distribu ted-Education-and-Its-Challenges-An-Overview.pdf

[10] Sonwalkar N. The pedagogical rating of online courses. Syllabus. 2002 Jan; 15(6): 8-21.

[11] Alley L, Jansak KE. The ten keys to quality assurance and assessment in online learning. J of Interactive Dev. 2001 Win; 13(3): 3-18.

[12] Valentine D. Distance learning: Promises, problems, and possibilities. Online J of Distance Learn Adm. 2002; 5(3). Available from: http://www.westga.edu/\%7Edistance/ojdla/f al153/valentine53.html

[13] Institute for Higher Education Policy. Quality on the line: Benchmarks for success in internet-based distance education. Washington, DC. 2000. Available from: http://www.ihep.org/sites/def ault/files/uploads/docs/pubs/qualityontheline.pdf

[14] OLC Quality Scorecard. Online Learning Consortium; 2014. Available from: http://onlinelearningconsortium.org/consu lt/quality-scorecard/

[15] Quality Online Course Initiative Rubric and Checklist (QOCI) [Internet]. University of Illinois; 2006. Available from: http://www . io n.uillinois.edu/initiatives/qoci/rubric.asp

[16] Quality Assurance Checklist. Central Michigan University Center for Instructional Design: 2003.

[17] Online Course Evaluation Project (OCEP). Monterey Institute: 2010. Available from: http://www .montereyinstitute.org/pdf /OC EP\%20Evaluation\%20Categories.pdf

[18] Online Course Development Guide and Rubric. University of Southern Mississippi Learning Enhancement Center: n.d. 2015. Avail- able from: http://ablendedmaricopa.pbworks.com/f/LEC _Online_course+rubric.pdf

[19] Rubric for Online Instruction. California State University, Chico: 2009. Available from: http://www.csuchico.edu/roi/docum ents/rubricpdf

[20] Online Course Development Guidelines and Rubric. Michigan Community College Association: 2014. Available from: http: //www . montereyinstitute.org/pdf /OCEP $\% 20$ Evalu ation\%20Categories.pdf

[21] Online Course Assessment Tool (OCAT) and Peer Assessment Process. Western Carolina University: 2007. Available from: https://www.wcu.edu/WebFiles/PDFs/facultycente r_OCAT_v2.0_25apr07.pdf

[22] Checklist for Online Interactive Learning (COIL) MacEwan University: n.d. 2015. Available from: https : //facultycommons.macewan.ca/wp-content/uploa $\mathrm{ds} /$ Checklist-for-Online-Interactive-Learning1.doc

[23] Quality Matters Program. Quality matters rubric workbook for higher education (2011-2013 Ed.) Annapolis, MD: MarylandOnline, Inc; 2011. 28p.

[24] Parscal T, Riemer D. Assuring quality in large-scale online course development. Online J of Distance Learn Adm. 2010; 8(2). Available from: http://www.westga.edu/ distance/ojdla/summer13 2/parscal_riemer132.html

[25] Puzziferro M, Shelton K. A model for developing high-quality online courses: Integrating a systems approach with learning theory. $\mathrm{J}$ of Asynchronous Learn Netw. 2008; 12(3-4): 119-136. Available from: http://files.eric.ed.gov/fulltext/EJ837519.pdf

[26] Finley D. Using Quality Matters (QM) to improve all courses. J of Teaching and Learn with Technol. 2012 Dec; 1(2): 48-50.

[27] Barczyk C, Buckenmeyer J, Feldman L. Mentoring professors: A model for developing quality online instructors and courses in higher education. Int J on E-Learning. $2010 \mathrm{Jan}$; 9(1): 7-26.

[28] Pollacia L, Russell J, Russell B. Developing an online program in computer information systems using Quality Matters ${ }^{\mathrm{TM}}$ standards. MERLOT J of Online Learning and Teaching. 2009 Jun; 5(2): 304 315. Available from: http://jolt.merlot.org/vol5no2/poll acia_0609.htm

[29] Shattuck K. What we're learning from Quality Matters-focused research: Research, practice, continuous improvement. 2012. Available from: https ://www . qualitymatters.org/what-were-learn ing-paperfinalmay-18-2012dec2012kspdf/download/Wha twe'relearningpaper_FINAL_May18, 2012_Dec2012ks.pdf

[30] Quality Matters Program. Quality matters rubric workbook for higher education (2011-2013 Ed.) Annapolis, MD: MarylandOnline, Inc; 2011. 28p.

[31] Dick WO, Carey L, Carey JO. The systematic design of instruction Boston, MA: Allyn \& Bacon, Inc. 2004.

[32] Neergaard MA, Olesen F, Andersen RS, et al. Qualitative description - the poor cousin of health research? BMC Med Res Methodology. 2009 Jul; 9(52): 1-5. http://dx.doi .org/10.1186/1471-228 8-9-52

[33] Pollacia L, McCallister M. Using web 2.0 technologies to meet Quality Matters ${ }^{\mathrm{TM}}$ (QM) requirements. J of Info Syst Educ. 2009; 20(2): 155-164.

[34] Monroe R. Instructional design and online learning: A quality assurance study. Dissertation Abstracts International. 2011.

[35] Shattuck K. What we're learning from Quality Matters-focused research: Research, practice, continuous improvement. 2012. Available from: https://www.qualitymatters.org/node/18 66/download/Whatwe\%27relearningpaper_FINAL_May18, 2 012_Dec2012ks.pdf 